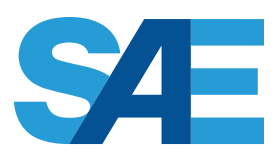

INTERNATIONAL.

\title{
Blending Octane Number of Ethanol on a Volume and Molar Basis in SI and HCCI Combustion Modes
}

\section{Muhammad Umer Waqas}

King Abdullah University of Science \& Tech

\section{Kai Morganti}

Saudi Aramco

\section{Jean-Baptiste Masurier and Bengt Johansson}

King Abdullah University of Science \& Tech

CITATION: Waqas, M., Morganti, K., Masurier, J., and Johansson, B., "Blending Octane Number of Ethanol on a Volume and Molar Basis in SI and HCCI Combustion Modes," SAE Technical Paper 2017-01-2256, 2017, doi:10.4271/2017-01-2256.

Copyright (C) 2017 SAE International

\begin{abstract}
The blending behavior of ethanol in five different hydrocarbon base fuels with octane numbers of approximately 70 and 84 was examined under Spark-Ignited (SI) and Homogeneous Charge Compression Ignited (HCCI) operating conditions. The Blending octane number $(\mathrm{BON})$ was used to characterize the blending behavior on both a volume and molar basis. Previous studies have shown that the blending behavior of ethanol generally follows several wellestablished rules. In particular, non-linear blending effects are generally observed on a volume basis (i.e. BON $>$ RON or MON of pure ethanol; 108 and 89, respectively), while linear blending effects are generally observed on a molar basis (i.e. $\mathrm{BON}=\mathrm{RON}$ or $\mathrm{MON}$ of pure ethanol). This work firstly demonstrates that the non-linear volumetric blending effects traditionally observed under SI operating conditions are also observed under HCCI operating conditions. In keeping with previous studies, the degree of this non-linearity is shown to be a function of the base fuel composition and octane number. By contrast, the molar blending approach is shown to behave differently depending on the chosen combustion mode, with some non-linearity observed under HCCI operating conditions (i.e. BON $\neq$ RON or MON of pure ethanol). This suggests that the wellestablished blending rules for SI operating conditions may not always be relevant to other combustion modes that operate with globally lean or diluted air-fuel mixtures. This has implications for the design of future fuel specifications.
\end{abstract}

\section{Introduction}

Gasoline produced in refineries often has a low octane rating [1] . Octane boosting compounds are therefore added into the gasoline to increase its octane rating and reduce its knocking tendency [1, 2 $]$. One of the first octane boosters was tetraethyl lead, which was added to gasoline in 1920s. Its use was later outlawed owing to environmental pollution, human health concerns and the widespread adoption of the three-way catalyst [ $\underline{3}]$. Methyl tert-butyl ether (MTBE) was subsequently identified as an effective replacement for lead in gasoline, and was widely utilized in the United States until recently []ㅡ. MTBE is now thought to be a potential human carcinogen, and can also accumulate in ground water [ $\underline{3}]$.

Today, the most popular octane boosters include aromatics and alcohols [4]. Alcohol fuels such as ethanol and methanol are attractive octane boosters as they have high octane ratings (RON $\sim 108$ ) and latent heats of vaporization (HoV) that are between four and seven times greater than gasoline on a stoichiometric basis. Exploiting these properties generally enables improved engine efficiency and reduced $\mathrm{CO}_{2}$ emissions $[\underline{5}, \underline{6}, \underline{7}, \underline{8}, \underline{9}]$. Ethanol is currently blended into gasoline in the form of E85 (51\% to $83 \%$ by volume depending on the season) in the United States, E100 or E22 in Brazil, E85 in Sweden and E10 in Australia [10, 11, 12, 13].

The Research and Motor octane numbers (RON and MON) are used to characterize the anti-knock quality of fuels under conditions relevant to spark-ignition (SI) engines $[\underline{14}, \underline{15}, \underline{16}]$. It is wellestablished that the RON increases in a non-linear manner when ethanol is blended with gasoline on volume basis $[\underline{17}, \underline{18}, \underline{19}, \underline{20}]$. A small percentage of ethanol can therefore lead to a disproportional increase in the octane number. Anderson et al. reported that $10 \%$ ethanol by volume caused a disproportionate increase in the RON of ethanol-gasoline blends [20]. The base fuel composition and octane number were shown to play an important role in this non-linear blending behavior $[\underline{17}, \underline{20}, \underline{21}, \underline{22}]$. To this end, base fuels with lower octane numbers provided a greater increase in the RON with $10 \%$ ethanol addition [20]. Similarly, Foong et al. blended ethanol into both a regular grade gasoline (RON 91) and Primary Reference Fuel (PRF) 91 [17]. The octane response was found to be more non-linear for PRF 91. This again reinforced that the composition of the base fuel plays an important role in the non-linear blending behavior of ethanol. 
The non-linear response of the RON with ethanol addition can conveniently be described using the Blending octane number (BON). The RON of pure ethanol is 108 , and if non-linear blending effects were not present, then the blending octane number would be a constant that is equal to the pure component octane number, i.e. 108 [17]. The blending octane number is a function of the base fuel composition, the RON of the mixture and the RON of the base fuel $[\underline{19}, \underline{22}]$ :

$$
R O N_{\text {base }} \cdot C_{\text {base }}+\text { BON. } C_{\text {booster }}=\text { RON }_{\text {mix }}
$$

where $R O N_{\text {base }}$ is the RON of the base fuel, $C_{\text {base }}$ is the concentration of the base fuel, $C_{\text {booster }}$ is the concentration of the booster and $R O N_{\text {mix }}$ is the octane number of the mixture (vol. \% or mol. \%).

For low octane booster concentrations, the $\mathrm{BON}$ is higher than the pure component octane number and gradually decreases as the concentration of booster is increased. It eventually converges to the RON of the octane booster at $100 \%$ concentration. The base fuel composition and octane number ultimately dictate the rate at which the BON decreases.

The findings from the above literature survey are all based on a volumetric blending approach. This is the industrial practice that is generally followed to produce fuels with the desired physical properties. However, these same trends may not be directly applicable if the blending is done on a molar basis. For example, it has been shown that the RON and MON increase in a linear manner when gasoline is blended with methanol on a molar basis [23] . In this case, the Blending octane number is equal to the octane number of pure methanol, and shows little dependence on the methanol concentration. The same authors also calculated the Blending octane number of ethanol on a molar basis using published data from several literature sources. It was again found that the Blending octane number data for ethanol was scattered around the octane number of pure ethanol, with little non-linear blending behavior observed [23] .

In our previous studies, experiments have been performed with FACE (Fuels for Advanced Combustion Engines) gasolines on a volume basis. These included FACE A, FACE I and FACE J gasolines along with their Primary Reference Fuel (PRF) surrogates. Ethanol was added to the base fuels in concentrations of $2 \%, 5 \%, 10 \%, 15 \%$ and $20 \%$. A standard Cooperative Fuel Research (CFR) engine was used to perform testing in both SI and HCCI combustion modes. For the SI combustion mode, the CFR was operated at standard RON conditions. This included an engine speed of $600 \mathrm{rpm}$, air inlet temperature of $52^{\circ} \mathrm{C}$ and spark timing (ST) of -13 CAD (Crank Angle Degrees). For the MON conditions, the engine was operated at a speed of $900 \mathrm{rpm}$, with the charge (air/fuel mixture) temperature maintained at $149^{\circ} \mathrm{C}$ and spark timing varied between -14 and -26 CAD.

For the HCCI combustion mode, a modified CFR engine was operated at the four conditions outlined in Table 1. For comparison with the RON and MON conditions, the test cases HCCI-1 and HCCI-4 were selected. The other two HCCI fuel numbers were selected to independently examine the effect of speed and inlet temperature on the ethanol blending behavior. Similarly, two HCCI numbers equivalent to the RON and MON were defined. To understand the effect of speed and inlet temperature on the HCCI fuel number, the engine speed (600-1200 rpm) and inlet temperature $\left(50^{\circ} \mathrm{C}-150^{\circ} \mathrm{C}\right)$ were varied by Truedsson et al.[24]. The HCCI operation was at $\lambda=3$, with the compression ratio adjusted to obtain CA50 of 3 CAD, i.e. 3 CAD after top dead center (aTDC).

Table 1. Test conditions for the four HCCI fuel numbers.

\begin{tabular}{|l|l|l|}
\hline HCCI fuel number & Engine speed (rpm) & $\begin{array}{l}\text { Intake air } \\
\left.\text { temperature } \text { Tin }^{(} \mathbf{C}\right)\end{array}$ \\
\hline HCCI-1 (RON) & 600 & 52 \\
\hline HCCI-2 & 600 & 149 \\
\hline HCCI-3 & 900 & 52 \\
\hline HCCI-4 (MON) & 900 & 149 \\
\hline
\end{tabular}

This study now examines the blending of ethanol with several FACE gasolines and their PRF surrogates on both a volume and molar basis. Most of the previous findings on the blending of ethanol are based on the SI combustion mode. Less is known about whether the molar and volume blending approaches are the same for the HCCI combustion mode. In particular, it is not clear whether the molar and volume blending approaches for the HCCI combustion mode follow the same well-established rules that are observed for the SI combustion mode. The volumetric blending data was obtained from a prior work [22]. In this study, analysis is performed on a molar basis and compared with the previous volumetric results. Finally, this study considers whether the base fuel octane number and composition plays any role in the observed blending behavior of ethanol when considered on a molar basis.

\section{Experimental Methods}

The RON and MON measurements were obtained in accordance with the standard ASTM test methods [25, 26]. For HCCI testing, a modified Waukesha variable compression ratio Cooperative Fuel Research (CFR) engine was used (Figure 1). The clearance volume was varied in order to change the compression ratio. The carburetor of the standard CFR engine was also replaced with a port-fuel injection (PFI) system. Table 2 summarizes the engine specifications and operating conditions.

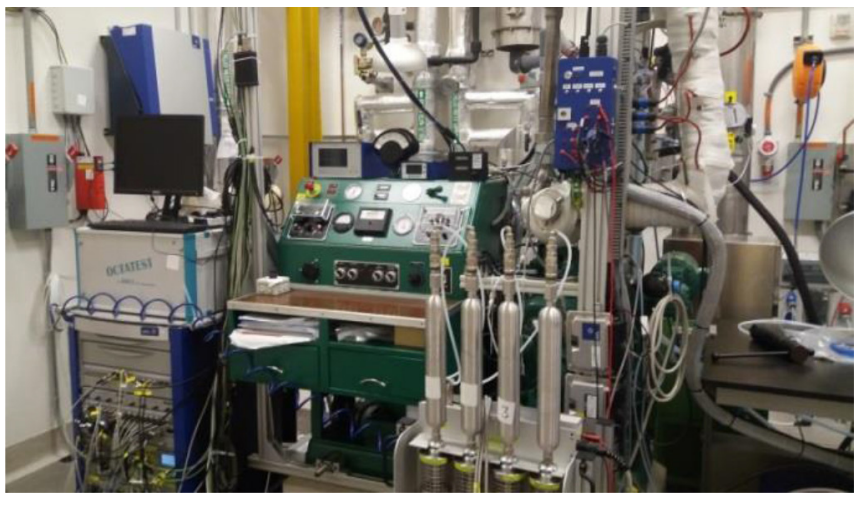

Figure 1. The modified CFR engine used for HCCI testing. 
Table 2. Specifications and operating conditions for the modified CFR engine used for HCCI testing.

\begin{tabular}{|l|l|}
\hline Engine Type & Single Cylinder CFR \\
\hline Injection System & Port-fuel Injection \\
\hline Bore & $82.55 \mathrm{~mm}$ \\
\hline Stroke & $114.3 \mathrm{~mm}$ \\
\hline Connecting Rod & $254 \mathrm{~mm}$ \\
\hline Compression ratio & Variable from $4: 1$ to $15: 1$ \\
\hline Speed & 600 to 900 rpm \\
\hline Spark timing (ST) & $-13 \mathrm{CAD}(\mathrm{Crank}$ Angle Degree) \\
\hline Minimum Intake Air Temperature & $52 \pm 2{ }^{\circ} \mathrm{C}$ \\
\hline Maximum Intake Air Temperature & $149 \pm 2{ }^{\circ} \mathrm{C}$ \\
\hline Lambda $(\lambda)$ & $3(\mathrm{HCCI})$ \\
\hline
\end{tabular}

\section{Test Fuels}

Three FACE gasolines (FACE A, FACE I and FACE J) were used in this study. The key fuel properties are summarized in Table 3. The PRF mixtures corresponding to RONs of 70 and 84 were also tested for comparative purposes. The five base fuels are classified as either low octane fuels (FACE I, FACE J and PRF 70) or high octane fuels (FACE A and PRF 84).

Table 3. Properties of FACE gasolines and their PRF surrogates.

\begin{tabular}{|l|l|l|l|l|l|}
\hline \multirow{2}{*}{ Fuels } & \multicolumn{3}{|c|}{ Low octane fuels } & \multicolumn{2}{c|}{ High octane fuels } \\
\cline { 2 - 6 } & $\begin{array}{c}\text { FACE } \\
\text { I }\end{array}$ & $\begin{array}{c}\text { FACE } \\
\text { J }\end{array}$ & PRF 70 & $\begin{array}{c}\text { FACE } \\
\text { A }\end{array}$ & $\begin{array}{c}\text { PRF } \\
84\end{array}$ \\
\hline RON & 70.2 & 73.8 & 70.0 & 83.9 & 84.0 \\
\hline MON & 69.5 & 70.1 & 70.0 & 83.5 & 84.0 \\
\hline Octane Sensitivity & 0.7 & 3.7 & 0.0 & 0.4 & 0.0 \\
\hline Aromatics (vol. \%) & 1.2 & 31.7 & 0.0 & 0.4 & 0.0 \\
\hline$n$-Paraffins (vol. \%) & 14.4 & 31.6 & 30.0 & 11.7 & 16.0 \\
\hline $\begin{array}{l}\text { Density (g/mL) } \\
\text { Molecular weight } \\
\text { (g/mol) }\end{array}$ & 0.679 & 0.735 & 0.690 & 0.674 & 0.691 \\
\hline
\end{tabular}

Previously, ethanol was added to the FACE gasolines and their PRF surrogates in concentrations of $2 \%, 5 \%, 10 \%, 15 \%$ and $20 \%$ by volume [22]. In this study, the volume percentages were converted to molar percentages using the fuel properties in Table 3 . The molar percentage of ethanol as a function of the volume percentage can be expressed as:

$$
\begin{gathered}
\text { Moles }(\%)=\left\{\frac{\left(\frac{\text { Mass fraction }}{\text { Molecular weight }}\right)_{\text {ethanol }}}{\left(\frac{\text { Mass fraction }}{\text { Molecularweight }}\right)_{\text {ethanol }}+\left(\frac{\text { Mass fraction }}{\text { Molecularweight }}\right)_{\text {base fuel }}}\right\}, \\
=\left\{\frac{\left(\frac{\text { Volume }(\%) \times \text { Density }}{\text { Molecular weight }}\right)_{\text {ethanol }}}{\left(\frac{\text { Volume }(\%) \times D \text { Density }}{\text { Molecularweight }}\right)_{\text {ethanol }}+\left(\frac{\text { Volume }(\%) \times \text { Density }}{\text { Molecularweight }}\right)_{\text {base fuel }}}\right\},
\end{gathered}
$$

$\underline{\text { Figures } 2}$ and $\underline{3}$ present the correlation between volume and molar percentages for the different base fuels. It can be observed that the molar percentages are nearly twice the value of the volume percentages. For example, $5 \%$ ethanol by volume in FACE I gasoline corresponds to $11.34 \%$ on a molar basis.

\section{Research Octane Number (RON) and Motor Octane Number (MON)}

The fuel autoignition properties in the SI combustion mode are characterized using the Research and Motor octane numbers (RON and MON) [14]. The RON and MON scales are arbitrarily defined based on two paraffinic fuels: iso-octane and $n$-heptane [14]. A value of 100 is assigned to iso-octane, while 0 is assigned to $n$-heptane.

\section{Homogeneous Charge Compression Ignition (HCCI) Fuel Number}

It has been recognized that the RON and MON are not well suited parameters for characterizing fuel autoignition in the HCCI combustion mode [27]. To understand the fuel performance in the HCCI combustion mode, several efforts were therefore made to identify more suitable indices that describe the practical autoignition characteristics [27]. Of all the indices, the Lund-Chevron HCCI number was found to best characterize fuel autoignition [27].

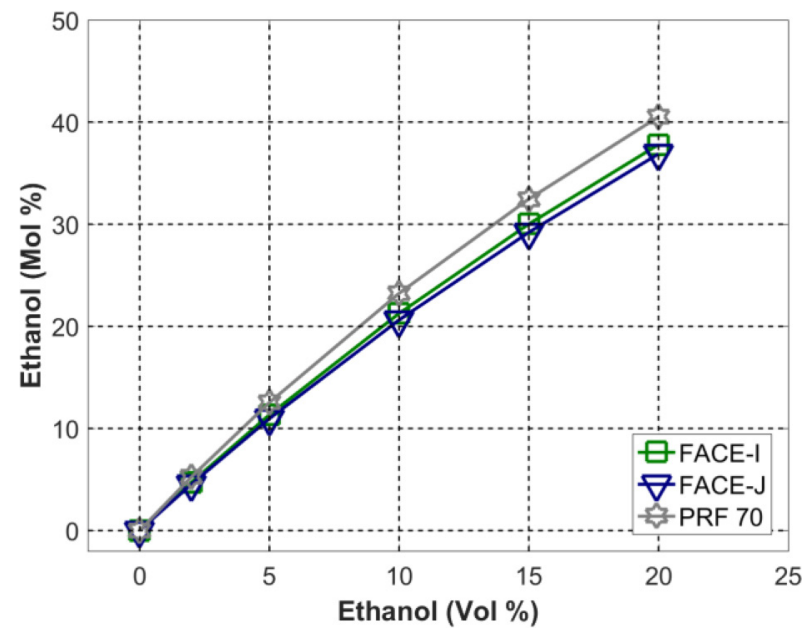

Figure 2. Correlation bettween volume and molar percentages for the low octane fuels.

The modified CFR engine was used to perform the HCCI testing. A transfer function was used to obtain the HCCI fuel numbers by testing PRFs in the range of 70 to 90 octane number. The experimentally derived compression ratio could then be converted to the equivalent PRF (Figure 4). The HCCI combustion mode was tested at four different operating conditions. The procedure for determining the HCCI fuel numbers involved finding the compression ratio that corresponded to a CA50 value (Crank Angle for 50\% heat release) of $3^{\circ}$ after top dead center (aTDC). A polynomial of best fit was obtained for each of the four operating conditions:

$$
\text { HCCI fuel number }=p R_{c}^{2}+q R_{c}+r,
$$


where HCCI fuel number represents the percentage of iso-octane by volume in the PRF mixture and $R c$ is the compression ratio. The values of the coefficients $p, q$ and $r$ are listed in Appendix C (Table A2). Further details on the transfer function can be found in a prior work [22].

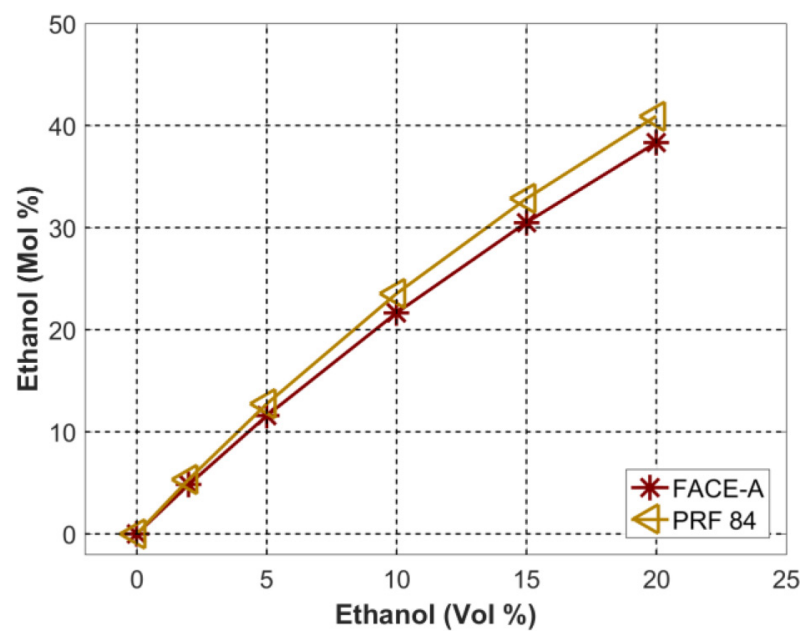

Figure 3. Correlation bettween volume and molar percentages for the high octane fuels.

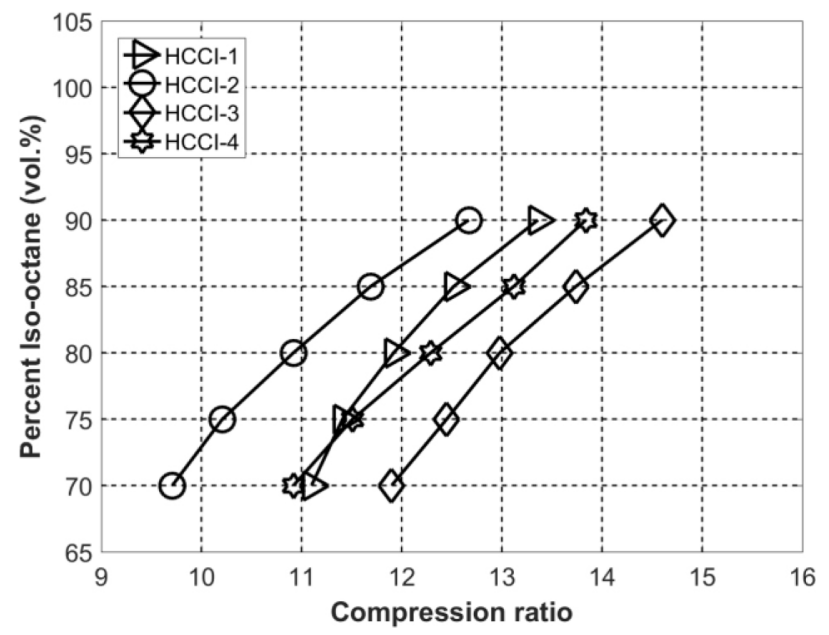

Figure 4. Transfer function for the four HCCI operating conditons, $\lambda=3$.

\section{Blending Octane Number (BON)}

The non-linear response of the RON with ethanol addition can be expressed using the Blending octane number $(\mathrm{BON})$. The $\mathrm{BON}$ is a function of the base fuel octane number (i.e. $0 \%$ ethanol), the concentration of the base fuel (FACE gasolines and PRFs), the booster concentration (ethanol) and the blending octane number $[\underline{17}, \underline{19}]$.

For the SI combustion mode, the BON (BRON and BMON) can be expressed as:

$$
\begin{gathered}
R O N_{\text {base }} \cdot C_{\text {base }}+B O N \cdot C_{\text {booster }}=R O N_{\text {mix }}, \\
B O N(S I)=\frac{R O N_{\text {mix }}-\text { RON }_{\text {base }} \cdot C_{\text {base }}}{C_{\text {booster }}}
\end{gathered}
$$

where $R O N_{\text {base }}$ represents the RON of the base fuel, $C_{\text {base }}$ is the concentration of the base fuel, $C_{\text {booster }}$ is the concentration of the booster and $R O N_{\text {mix }}$ is the octane number of the mixture (either vol. $\%$ or mol. \%). The RON term is simply replaced with the MON for Motor octane number test conditions.

For the HCCI combustion mode, Equation 5 can be expressed as:

$$
\begin{gathered}
H C C I_{\text {base }} \cdot C_{\text {base }}+B O N . C_{\text {booster }}=H C C I_{\text {mix }}, \\
B O N(B H C C I)=\frac{H C C I_{\text {mix }}-H_{C C I_{\text {base }}} \cdot C_{\text {base }}}{C_{\text {booster }}},
\end{gathered}
$$

where $\mathrm{HCCI}_{\text {base }}$ represents the HCCI fuel number for the base fuel ( $0 \%$ ethanol), $C_{\text {base }}$ is the concentration of the base fuel, $C_{\text {booster }}$ is the concentration of the booster and $\mathrm{HCCI}_{\text {mix }}$ is the HCCI fuel number of the mixture (vol. \% or mol. \%.).

\section{Results}

\section{Spark-Ignition Combustion Mode}

Ethanol was blended with the five base fuels in concentrations of $2 \%$, $5 \%, 15 \%$ and $20 \%$. The resulting RON, MON, BRON and BMON will be discussed in the following section on both a volume and molar basis.

Figures 5 and 6 present the increase in the Research octane number with the addition of ethanol on a volume and molar basis, respectively. As expected, the trend for the RON was the same on both a volume and molar basis, with the exception that the ethanol percentage on a molar basis is almost twice that of the volume percentage. This is because the RON was obtained experimentally using volume concentrations. To understand the blending behavior on a molar basis, only the volume concentrations must be converted to molar concentrations using Equation 3.

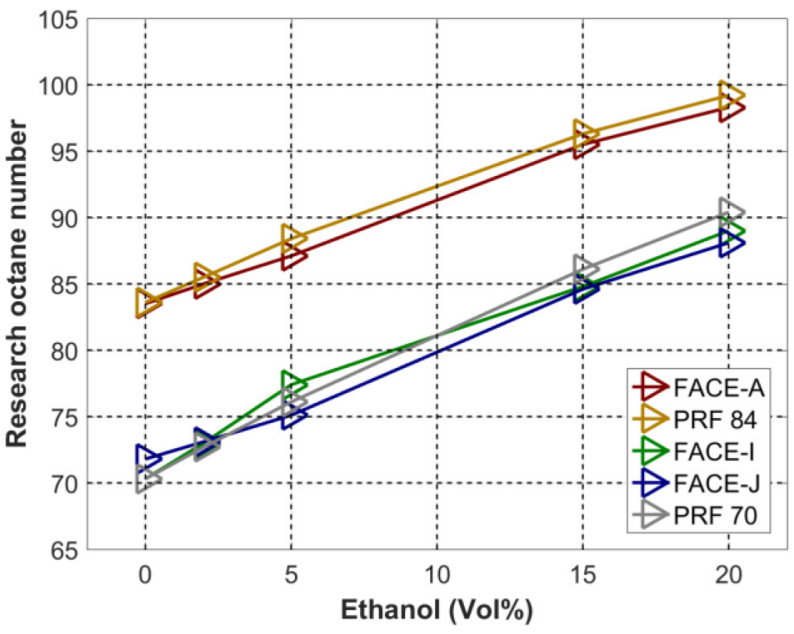

Figure 5. Research octane number (RON) for FACE gasolines and PRFs versus ethanol percentage. 


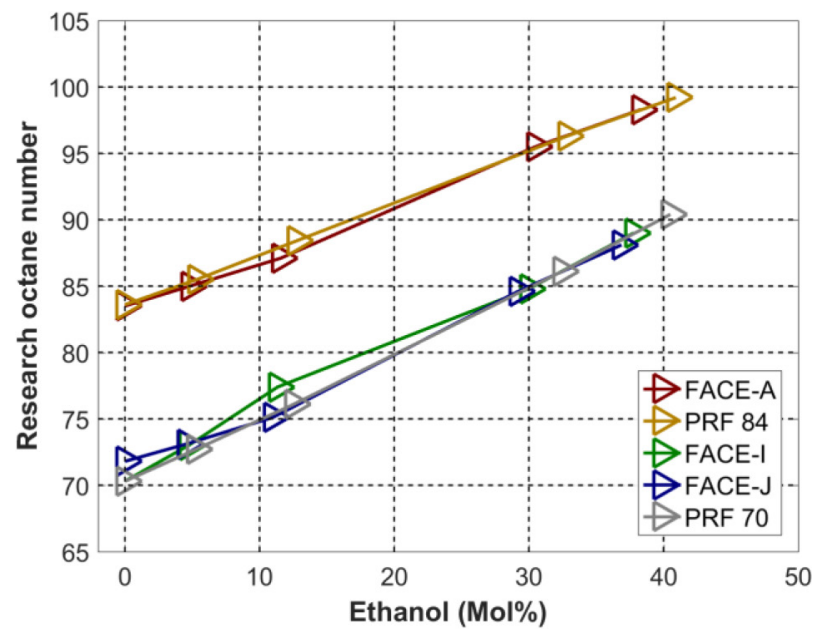

Figure 6. Research octane number (RON) for FACE gasolines and PRFs versus ethanol percentage.

For the low octane fuels (FACE I, J and PRF 70), the RON increased from around 70 to 90 , thereby showing an improvement of 20 units for up to $20 \%$ ethanol addition (Figs. 5 and $\underline{6}$ ). For the high octane fuels (FACE A and PRF 84), the RON increased from 84 to 99. This demonstrates that ethanol is a better octane enhancer for the low octane fuels, which is consistent with other studies in the literature $[\underline{19}, \underline{28}]$.

Figures 7 and $\underline{8}$ present the Motor octane number variation with ethanol addition on a volume and molar basis, respectively. For the low octane fuels (FACE I, J and PRF 70), an increase of 10 to 15 units is observed. For the high octane fuels (FACE A and PRF 84), a 6 to 8 unit increase is observed with ethanol addition (Figs. 7 and $\underline{8}$ ). The increase in the MON is not as large as observed when the engine was operated at the RON test conditions (Figs. 5 and $\underline{6}$ ). This trend is observed for all base fuels.

As the engine speed is increased to $900 \mathrm{rpm}$ with the inlet air/fuel temperature set at $149^{\circ} \mathrm{C}$, ethanol behaves as a weaker octane enhancer. One common trend for both the RON and MON conditions is that a greater increase in the octane number is observed for base fuels with lower octane numbers. A saturation effect is also observed at higher ethanol concentrations, i.e. above $15 \%$ by volume. This occurs for all FACE gasolines and PRF 84, but is not observed for PRF 70. It is known that at low ethanol concentrations, octane sensitivity of the blend increases significantly [17]. With the increasing concentrations of ethanol, the octane sensitivity becomes independent of the ethanol content [17]. Other studies have highlighted that at low ethanol concentrations, a significant increase in the RON is observed, which is consistent with our study $[\underline{17}, \underline{18}$, $\underline{19}, \underline{20}, \underline{22}]$. Another study on understanding the chemical kinetics behind ethanol blending has shown that ethanol is an effective booster at low concentrations $[\underline{29}, \underline{30}]$. There is still a lack of understanding behind the ethanol blending with gasoline at high ethanol concentrations [17]. The above explanations could possibly be the reasons for the saturation behavior observed in our study. Similar observations have also been reported elsewhere in the literature [31].

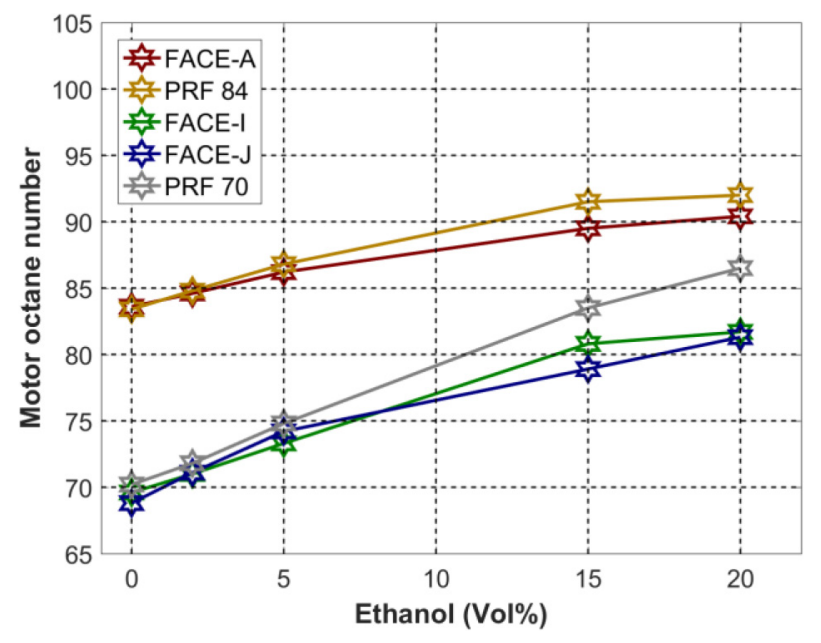

Figure 7. Motor octane number (MON) for FACE gasolines and PRFs versus ethanol percentage.

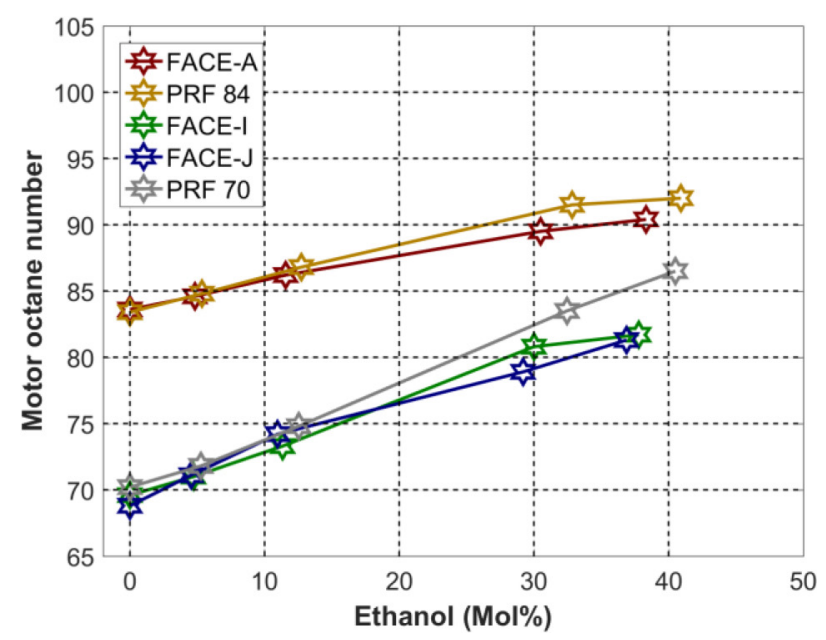

Figure 8. Motor octane number (MON) for FACE gasolines and PRFs versus ethanol percentage.

Figure 9 presents the Blending Research octane number (BRON) for ethanol with the five base fuels on a volume basis. The Blending Research octane number is higher than the Research octane number of pure ethanol, and therefore non-linear effects are present. Among the low octane fuels, FACE J has the lowest Blending Research octane number for all ethanol concentrations and the BRON range is 140 to 160 . FACE $\mathrm{J}$ has a higher aromatic content than FACE I and PRF 70. It appears that in the presence of the high aromatic content, ethanol does not act as a strong octane enhancer. This is consistent with the observations in Ref [17]. At low ethanol concentrations, FACE I provided the highest Blending research octane numbers. The BRONs for FACE I ranged from 170 to 210 . PRF 70 appears to behave differently to FACE I and FACE J at low ethanol concentrations. But at higher ethanol concentrations, PRF 70 and FACE I behave in a somewhat similar manner.

For the high octane fuels, FACE A appears to have a constant BRON value of around 160. PRF 84 behaves differently to FACE A at low ethanol concentrations, with a higher BRON value of 180 observed at $2 \%$ ethanol addition. This decreases to 170 at $20 \%$ ethanol content. Overall, this suggests that ethanol has a different octane enhancement effect for the low and high octane fuels, especially at low ethanol 
concentrations where the BRON varies significantly. The large variation of $\mathrm{BRON}$ at $2 \%$ concentration for all base fuels could be due to the uncertainty analysis discussed in Appendix D.

It has previously been found that the addition of ethanol to a base fuel with a RON of 71 resulted in a higher BRON than the same amount of ethanol addition to a base fuel with a RON of 91 [19]. In the present study, at low ethanol concentrations, FACE I and PRF 70 have higher BONs than FACE A and PRF 84. At higher ethanol concentrations, only PRF 70 has a higher BRON value when compared with the other base fuels. FACE J, which has a higher aromatic content, also has a RON close to 70 but results in the lowest Blending octane number. This is not consistent with the previous findings for the $70 \mathrm{ON}$ fuel [19]. This suggests that both the base fuel octane number and the composition of the base fuel influences the blending response of the mixture to ethanol. This is consistent with the previous findings $[\underline{22}, \underline{32}]$.

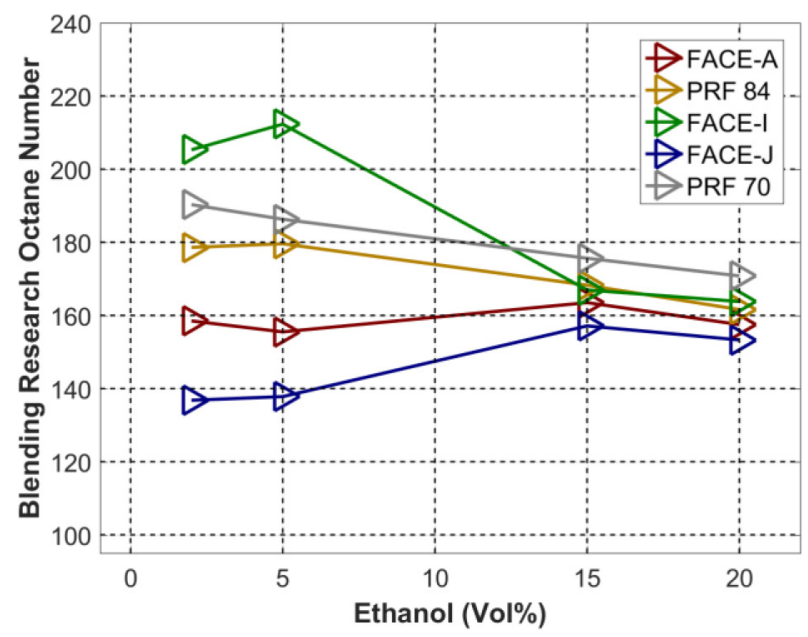

Figure 9. Blending Research octane number (BRON) for FACE gasolines and PRFs versus ethanol percentage.

Figure 10 presents the Blending Research octane number of ethanol on a molar basis. The RON of pure ethanol is 108. At low ethanol concentrations, the BRON values for all the base fuels except FACE J are higher than 108 , thereby demonstrating a weak non-linear effect. When compared with the volumetric results, the BRON values are lower for all base fuels. This demonstrates that a much weaker non-linear effect is present on a molar basis.

FACE I shows the strongest non-linear effect, with a BRON in the range of 120 to 130. FACE $\mathrm{J}$ has an octane number that is close to FACE I. However, this fuel has a greater aromatic and $n$-paraffinic content than FACE I. At low ethanol concentrations, both of these fuels behave differently, but at higher ethanol concentrations, the compositional effect is negligible. FACE A, PRF 84 and PRF 70 behave somewhat similarly, with a BRON value close to 120 . A weaker base fuel octane number effect is observed at low ethanol concentrations. However, with increasing ethanol concentration, this effect diminishes. Overall, it can be concluded that a much weaker non-linear effect is present for the molar blending approach in comparison with the volumetric blending approach. This is expected since the molar percentage is higher than the volume percentage. Nevertheless, some minor non-linear effects are often observed.

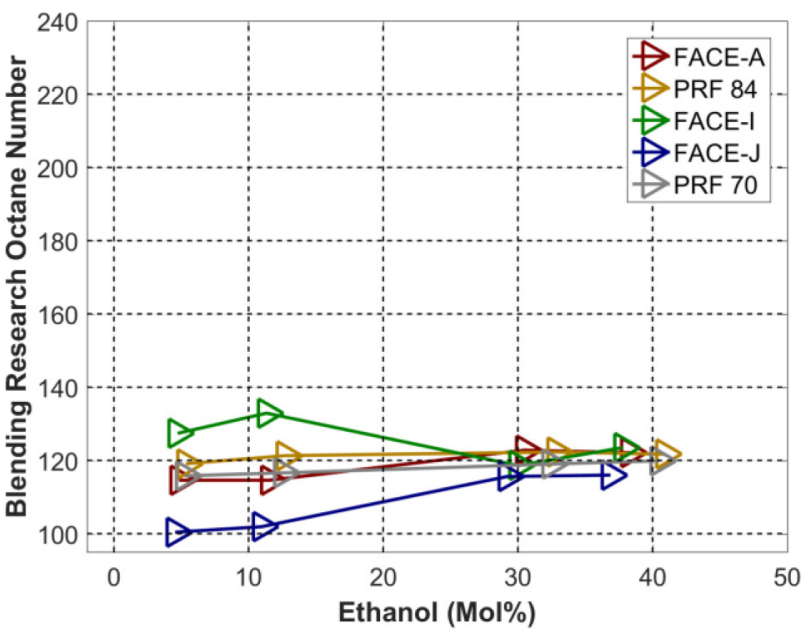

Figure 10. Blending Research octane number (BRON) for FACE gasolines and PRFs versus ethanol percentage.

Figure 11 presents the blending Motor octane number (BMON) for the five base fuels on a volume basis. The combined effect of increasing the engine speed and the air/fuel inlet temperature leads to weaker octane enhancement effect from ethanol for all base fuels in comparison with the RON test conditions (Fig. 9). The weaker octane enhancement could be due to the MON operating conditions. At MON conditions, the heat of vaporization of the fuel is removed, which is likely to reduce the octane enhancement effect of ethanol. This was not observed for FACE J at low ethanol concentrations, which instead exhibits an improvement in the BMON values. It has been shown that ethanol acts as a better octane enhancer at low concentrations [20-21]. This should be applicable to all base fuels, but higher BMON values for FACE J at low concentrations most likely reflects the compositional effect on the blending behavior. Uncertainties in the calculation of the BMON could also be a contributing factor. This is discussed in Appendix D.

Both FACE A and PRF 84 exhibit a similar decay rate to PRF 84, with each having higher BMON values than FACE A. This trend was also observed at the RON test conditions. The different slopes of the low octane fuels (FACE I, J and PRF 70) suggests that even though the octane number is close to 70 , the compositional effect plays an important role in the blending behavior.

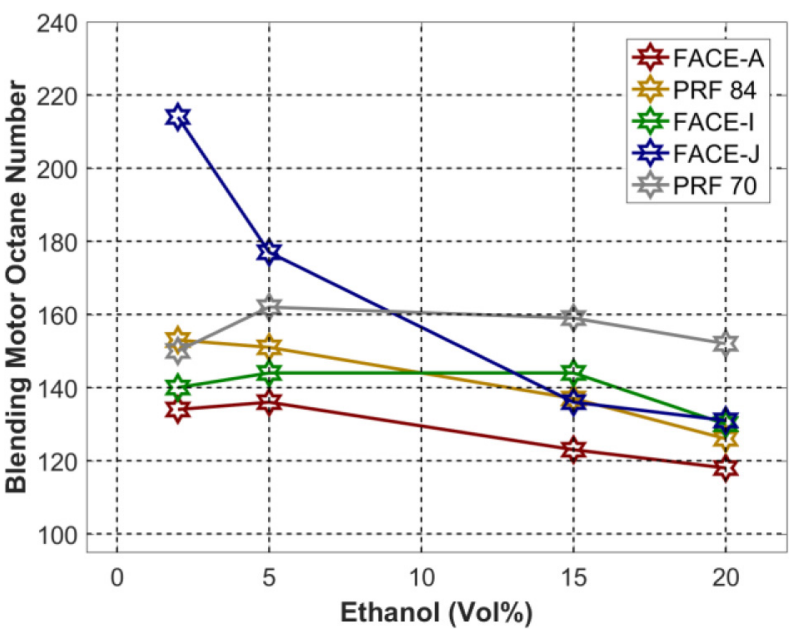

Figure 11. Blending Motor octane number (BMON) for FACE gasolines and PRFs versus ethanol percentage. 
Figure 12 presents the Blending Motor octane number (BMON) for the five base fuels on a molar basis. A weaker octane enhancement is observed for all base fuels with the exception of FACE J at low ethanol concentrations in comparison with the RON test conditions (Fig.10). The MON of ethanol is 89 . The BMON values for all the base fuels are around 100, and therefore a weak non-linear blending effect is present. The BMON values fall in the range of 100 to 110 for all the base fuels. Additionally, the slopes of the different base fuels collapse. It therefore appears that at the higher engine speed of 900 rpm and charge temperature of $149^{\circ} \mathrm{C}$, the base fuel composition and octane number effects both become negligible.

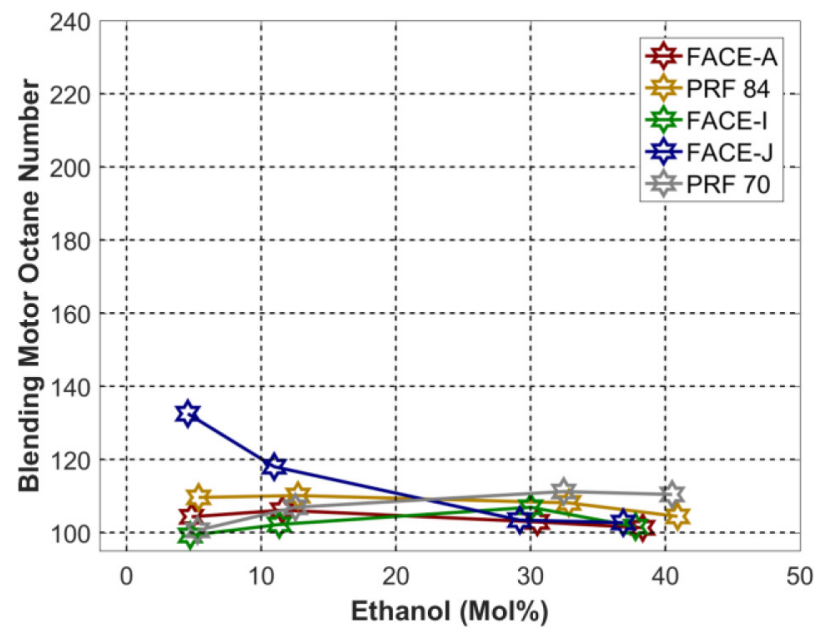

Figure 12. Blending Motor octane number (BMON) for FACE gasolines and PRFs versus ethanol percentage.

\section{HCCI Results}

Figures 13 and $\underline{14}$ present the Blending HCCI octane numbers for the three FACE gasolines and two PRFs on a volume and molar basis, respectively. The Blending HCCI octane numbers (BHCCI) \#1, \#2, $\# 3$ and \#4 represent the four HCCI conditions described earlier in Table 1. Some of the plots for the HCCI results do not include all the data points. This is due to the limitation on the compression ratio of the test engine.

The overall Blending HCCI octane number (BHCCI \#1) range on a volume basis is 130 to 210 . On a molar basis, the range was reduced to 100 to 130 , thereby showing a much weaker non-linear effect. This is consistent with the SI combustion mode results for the RON test conditions (Figs. 9 and 10). Similar to the SI combustion mode, some uncertainty exists in the calculation of the BHCCI \#1 values at $2 \%$ ethanol concentration. This is discussed in Appendix D. At low ethanol concentrations, the Blending HCCI octane numbers for FACE $A$ and PRF 84 are shown to be higher than FACE I, FACE J and PRF 70. But with increasing ethanol concentrations, there is a sharp decrease. FACE I and J have different aromatic content and therefore behave differently on both a volume and molar basis. The Blending HCCI octane numbers (BHCCI \#1) for all five base fuels are well scattered when considered in volumetric terms. However, on a molar basis, it appears that the slopes are much less scattered. This suggests that the effects of the base fuel composition and octane number are relatively weak on a molar basis.

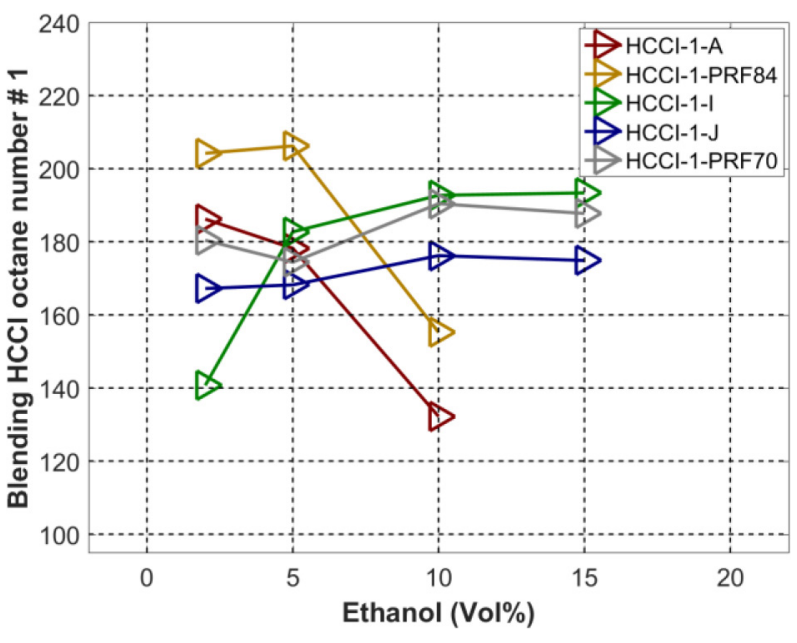

Figure 13. Blending HCCI octane number (BHCCI \#1) for FACE gasolines and PRFs versus ethanol percentage $\left(600 \mathrm{rpm}, \mathrm{T}_{\text {in }}=52^{\circ} \mathrm{C}\right.$ and $\left.\lambda=3\right)$.

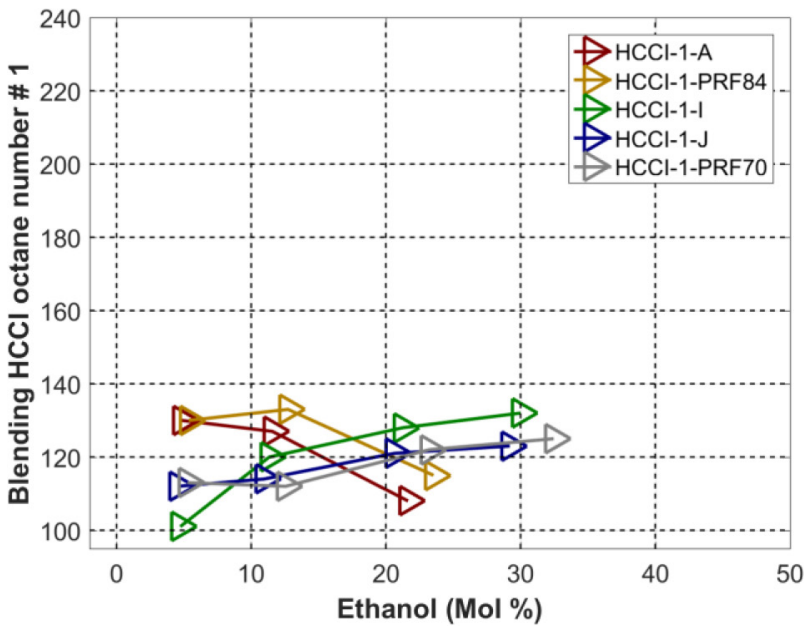

Figure 14. Blending HCCI octane numbers (BHCCI \#1) for FACE gasolines and PRFs versus ethanol percentage $\left(600 \mathrm{rpm}, \mathrm{T}_{\mathrm{in}}=52^{\circ} \mathrm{C}\right.$ and $\left.\lambda=3\right)$.

Figures 15 and 16 present the data for Blending HCCI octane number (BHCCI \#2). In this case, the engine speed was maintained at 600 $\mathrm{rpm}$, but the inlet air temperature was increased to $149^{\circ} \mathrm{C}$. The overall Blending HCCI octane number (BHCCI \#2) range is 130 to 210 on a volume basis. This is reduced to 110 to 135 on a molar basis, thereby demonstrating much weaker non-linear effects. The Blending HCCI octane number range for the volume and molar approaches is found to be the same for both the low and high inlet temperatures, which both demonstrate similar non-linear effects.

Overall, the observed trends for the different base fuels is quite similar on both a volume and molar basis (igs. 15 and 16). For the high octane fuels (FACE A and PRF 84), a large negative slope is generally observed. While for the low octane fuels (FACE I, FACE J and PRF 70), an increasing slope is observed. On a volume basis, FACE J shows the lowest BHCCI \#2 when compared with FACE I and PRF 70. 


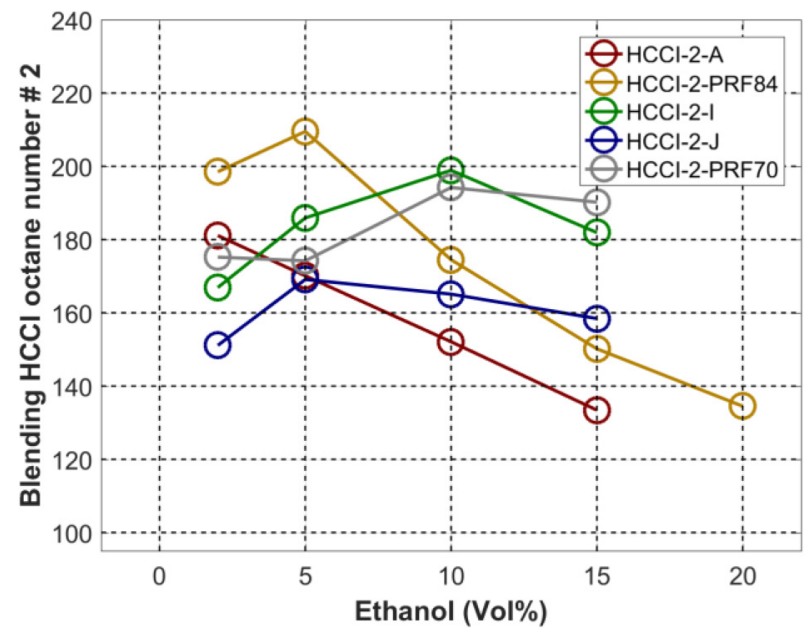

Figure 15. Blending HCCI octane number (BHCCI \#2) for FACE gasolines and PRFs versus ethanol percentage $\left(600 \mathrm{rpm}, \mathrm{T}_{\text {in }}=149^{\circ} \mathrm{C}\right.$ and $\left.\lambda=3\right)$.

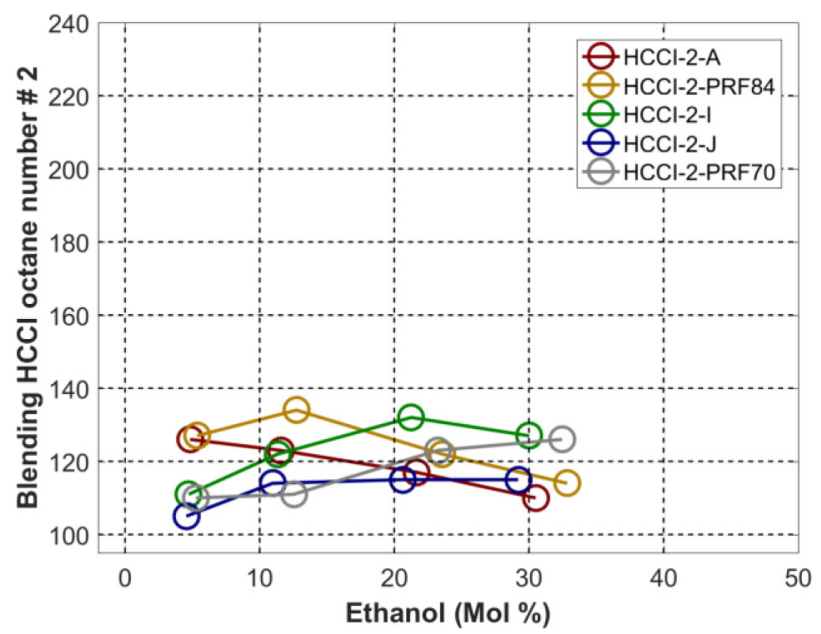

Figure 16. Blending HCCI octane number (BHCCI \#2) for FACE gasolines and PRFs versus ethanol percentage $\left(600 \mathrm{rpm}, \mathrm{T}_{\text {in }}=149^{\circ} \mathrm{C}\right.$ and $\left.\lambda=3\right)$.

$\underline{\text { Figures } 17}$ and $\underline{18}$ present the data for Blending HCCI octane number (BHCCI \#3). In this case, the engine speed is increased to $900 \mathrm{rpm}$, with the inlet air temperature maintained at $52^{\circ} \mathrm{C}$. The overall BHCCI \#3 for low octane base fuels is 170 to 220 on a volume basis. The increase in the engine speed has increased the BHCCI \#3 values for the low octane fuels when compared with the lower engine speed of $600 \mathrm{rpm}$ with the inlet temperature maintained at $52^{\circ} \mathrm{C}(\underline{\text { Fig. } 13})$. Among the low octane fuels, FACE J still has the lowest BHCCI \#3, as previously observed for the lower engine speed (Fig.13). For FACE A and PRF 84, the octane enhancement from ethanol has weakened in comparison with lower engine speed of $600 \mathrm{rpm}$ (Fig.13).

On molar basis, the overall BHCCI \#3 range is 120 to 130 for all the base fuels. For some of the base fuels, a BHCCI \#1 value that is lower than 120 was observed at the low engine speed (Fig.14). However, as the engine speed is increased to $900 \mathrm{rpm}$, a greater octane enhancing effect is observed, with a higher BHCCI \#3 in comparison with BHCCI \#1. Overall, the slopes for the base fuels almost collapse when considered on a molar basis.

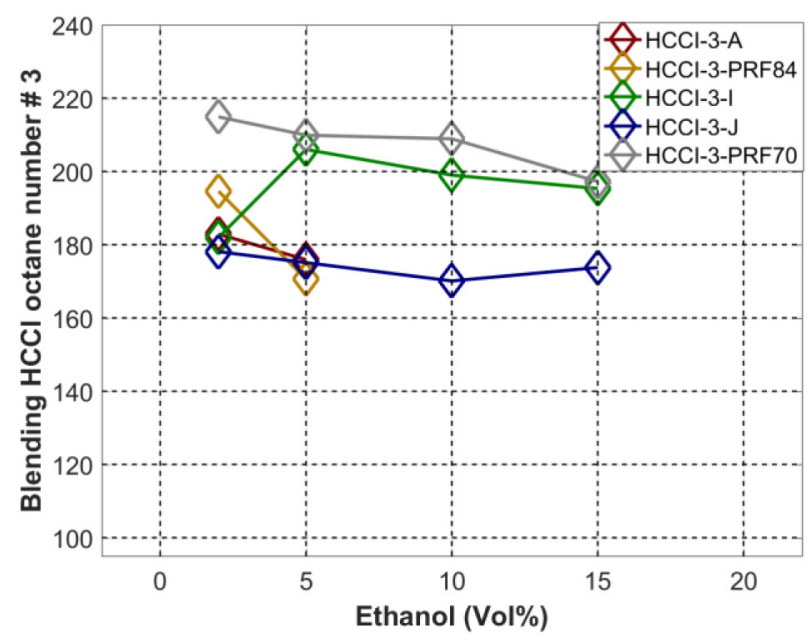

Figure 17. Blending HCCI octane number (BHCCI \#3) for FACE gasolines and PRFs versus ethanol percentage $\left(900 \mathrm{rpm}, \mathrm{T}_{\text {in }}=52^{\circ} \mathrm{C}\right.$ and $\lambda=3$ ).

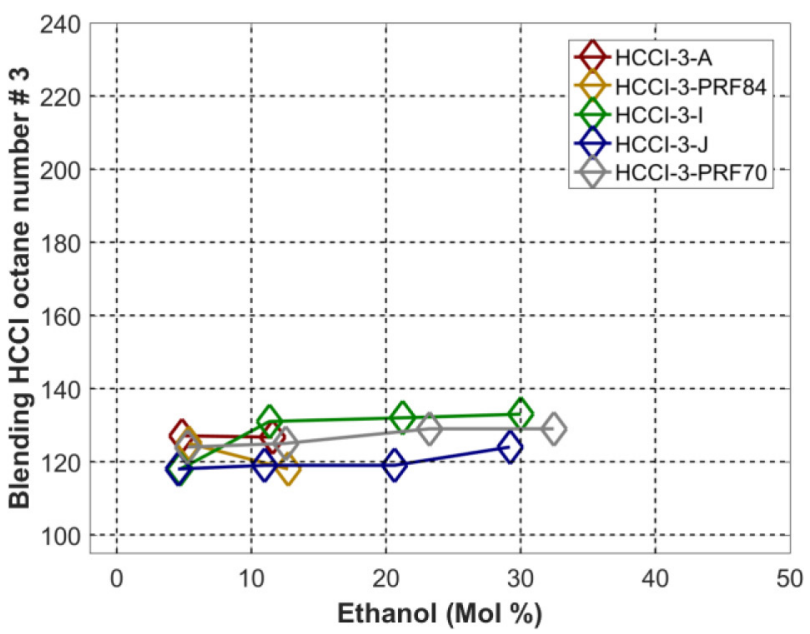

Figure 18. Blending HCCI octane number (BHCCI \#3) for FACE gasolines and PRFs versus ethanol percentage ( $900 \mathrm{rpm}, \mathrm{T}_{\mathrm{in}}=52^{\circ} \mathrm{C}$ and $\lambda=3$ ).

Figures 19 and $\underline{20}$ present the combined effect of high intake temperature and engine speed, which corresponds to the MON conditions in the SI engine tests $\left(900 \mathrm{rpm}\right.$ and $149^{\circ} \mathrm{C}$ respectively). The overall (BHCCI \#4) was in the range of 110 to 250 on a volume basis, but was reduced to 100 to 150 on a molar basis. Ethanol had a better octane enhancing effect on the low octane fuels, with higher BHCCI \#4 values generally observed, except at low ethanol concentrations. This was the case on both a volume and molar basis. Of the five base fuels, only PRF 70 showed a positive slope, followed by a negative slope at high ethanol concentrations. FACE A showed the lowest BHCCI \#4 values.

On a molar basis, the BON data for BHCCI \#1, BHCC1 \#2 and BHCCI \#3 almost collapses for all of the base fuels. However, with the combined effect of speed and inlet air temperature, this is not the case. It appears that the base fuel octane number and composition therefore have a stronger influence at the BHCCI \#4 test condition. In the case of the SI combustion mode (ig.10), each of the slopes collapse. However, the same observations are not present for the lean combustion mode (HCCI) at the same operating conditions.

Overall, it can be observed that for the base fuels with an octane number of 84 , the slopes for the BHCCI were negative. For the base fuels with an octane number of 70 , the slopes were positive or 
constant. This observation is consistent for BHCCI \#1, \#2 and \#3. This may be due to the different blending characteristics of ethanol with base fuels of different composition and octane number. It has previously been found that ethanol acts as a radical scavenger when

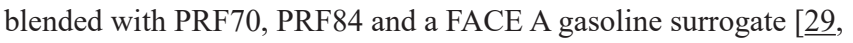
30]. The chemical kinetic simulations showed that the magnitude of low temperature heat release (LTHR) decreased at different rates with the addition of ethanol for each of these base fuels [29, 30]. This again reinforces that ethanol behaves differently with each of the base fuels. The reduction in the LTHR was found to have a link with the non-linear increase of ON $[\underline{29}, \underline{30}]$. The observed trends could be due to such chemical kinetic considerations.

For BHCCI \#4, the slopes are observed to be somewhat steeper. At BHCCI \#4, the inlet air temperature is higher, which causes ethanol to be more reactive due to its high octane sensitivity [33]. The high reactivity of ethanol means that it does not remain as effective as an octane booster as was the case in BHCCI \#1. It has been observed that with the increasing inlet air temperature, the LTHR is drastically suppressed [30]. From a chemical kinetic perspective, the evolution of the $\mathrm{OH} / \mathrm{HO}_{2}$ ratio does not show any peak rise, which is the main reason behind the absence of LTHR at high inlet air temperatures [30]. This could be the reason why such trends are observed for BHCCI \#4.

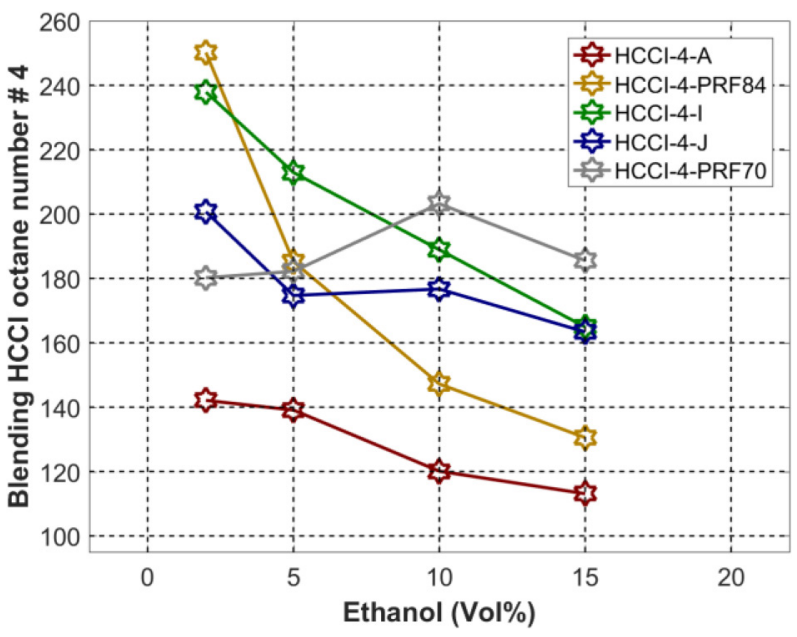

Figure 19. Blending HCCI octane number (BHCCI \#4) for FACE gasolines and PRFs versus ethanol percentage $\left(900 \mathrm{rpm}, \mathrm{T}_{\mathrm{in}}=149^{\circ} \mathrm{C}\right.$ and $\left.\lambda=3\right)$.

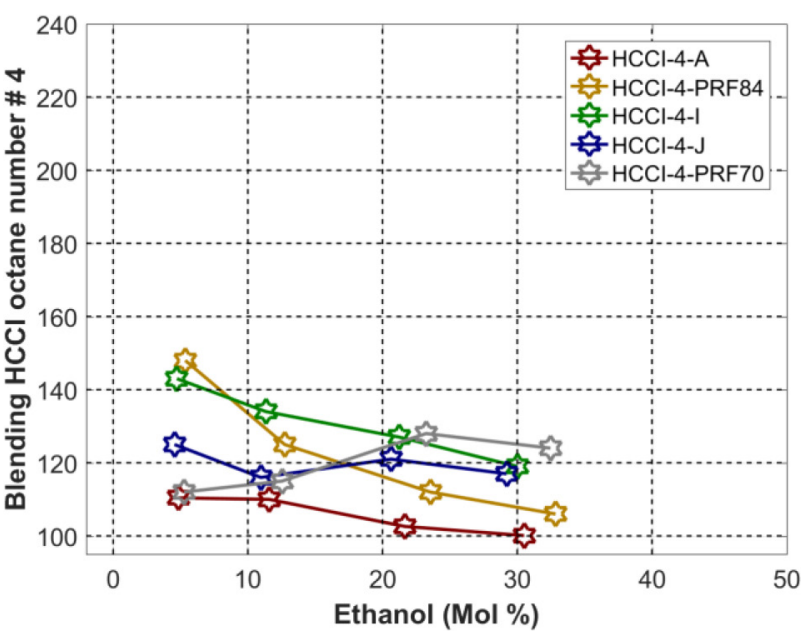

Figure 20. Blending HCCI octane number (BHCCI \#4) for FACE gasolines and PRFs versus ethanol percentage $\left(900 \mathrm{rpm}, \mathrm{T}_{\mathrm{in}}=149^{\circ} \mathrm{C}\right.$ and $\left.\lambda=3\right)$.

\section{SI Combustion Mode vs HCCI Combustion Mode}

This section presents the data for all the base fuels in both the SI and HCCI combustion modes. The mole percentages of ethanol shown on the $\mathrm{x}$-axes are approximately equivalent to twice the volume percentages. For example, $10 \%$ by volume is equivalent to $21.26 \%$ on a molar basis.

Figures 21 and 22 present the Blending octane numbers on a volume basis for both the SI and HCCI combustion modes, respectively. The RON (HCCI-1) and MON (HCCI-4) of pure ethanol are designated by horizontal lines. Since the modified CFR engine had hardware limitations, it was not possible to measure the HCCI fuel numbers for pure ethanol. Using the data from the base fuel testing, a correlation between the RON and HCCI \#1 as well as the MON and HCCI \#4 was found. It was estimated that HCCI-1 for pure ethanol was 111, while HCCI-4 was 87.

The BRON (BHCCI \#1) and BMON (BHCCI \#4) values are higher than the RON (HCCI\#1) and MON (HCCI \#4) values of pure ethanol, and hence non-linear effects are observed on a volume basis for both the SI and HCCI combustion modes. For the SI combustion mode results, this is consistent with the findings of Anderson et al. for methanol and ethanol [23] . In order to have no non-linear effects, the BRON (BHCCI \#1) must be equal to the RON (HCCI \#1) and the BMON (BHCCI \#4) must be equal to the MON (HCCI\# 4) of pure ethanol. In the SI combustion mode, the BRON values appear to be higher than BMON values, thereby indicating that the non-linear behavior is quite different at the two different engine speeds of 600 and $900 \mathrm{rpm}$. The inlet temperature of $149^{\circ} \mathrm{C}$ is also likely to play a role in the lower values of the BMON.

For the HCCI combustion mode, both the BHCCI \#1 and BHCCI \#4 values are well scattered, which is a key point of difference to the SI combustion mode. Some of the overlapping between the BHCCI \#1 and BHCCI \#4 values indicates that similar non-linear behavior was present when increasing the inlet speed to $900 \mathrm{rpm}$ and the inlet temperature to $149^{\circ} \mathrm{C}$. Overall, this suggests that the combustion mode plays an important role in the blending behavior of ethanol with the different base fuels.

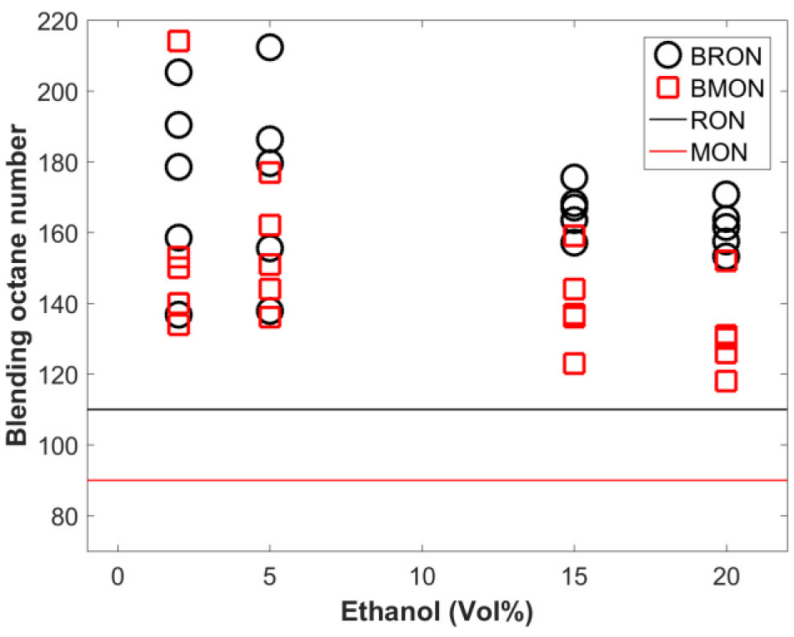

Figure 21. Blending octane number (BRON and BMON) in SI combustion mode versus ethanol percentage on a volume basis. Horizontal lines represent the RON and MON of pure ethanol. 


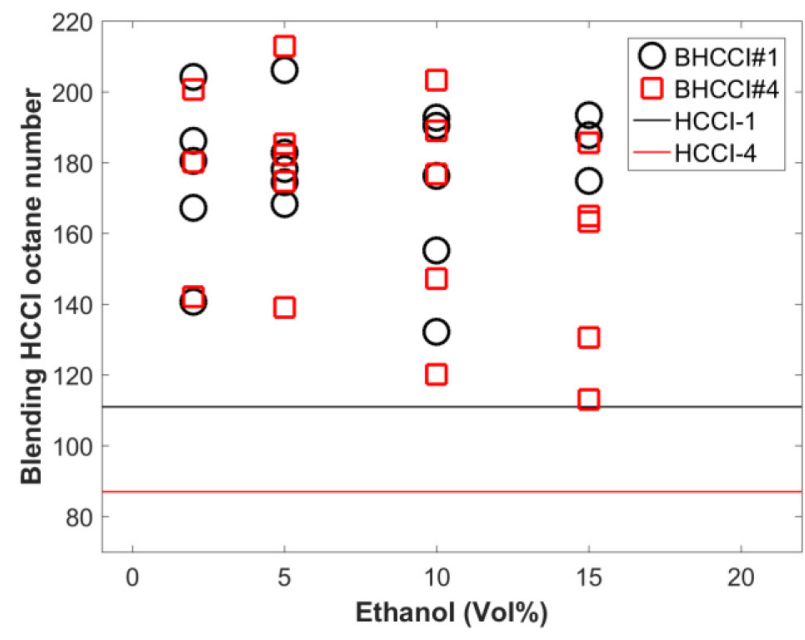

Figure 22. Blending octane numbers (BHCCI \#1 and BHCCI \#4) in HCCI combustion mode versus ethanol percentage on a volume basis. Horizontal lines represent the HCCI-1 and HCCI-4 of pure ethanol.

$\underline{\text { Figures } 23}$ and $\underline{24}$ present the Blending octane numbers on a molar basis for both the SI and HCCI combustion modes, respectively. In the SI combustion mode, the BRON and BMON values are scattered close to the RON and MON values of pure ethanol, respectively. These results are consistent with the findings of Anderson et al [르] . The non-linear effects are much weaker when considered on a molar basis. For the HCCI combustion mode, the data for both BHCCI \#1 and BHCCI \#4 is not particularly well scattered around HCCI \#1 and HCCI \#4, as observed for the SI combustion mode. Further, the BHCCI \#4 values exhibit more non-linear behavior than the BHCCI \#1 values.

Overall, it is apparent that the combustion mode plays an important role in determining the non-linear behavior associated with ethanol in different base fuels. Ethanol appears to have a different blending effect under lean and stoichiometric combustion modes. This can be observed from the different values of the Blending octane numbers in the SI and HCCI combustion modes.

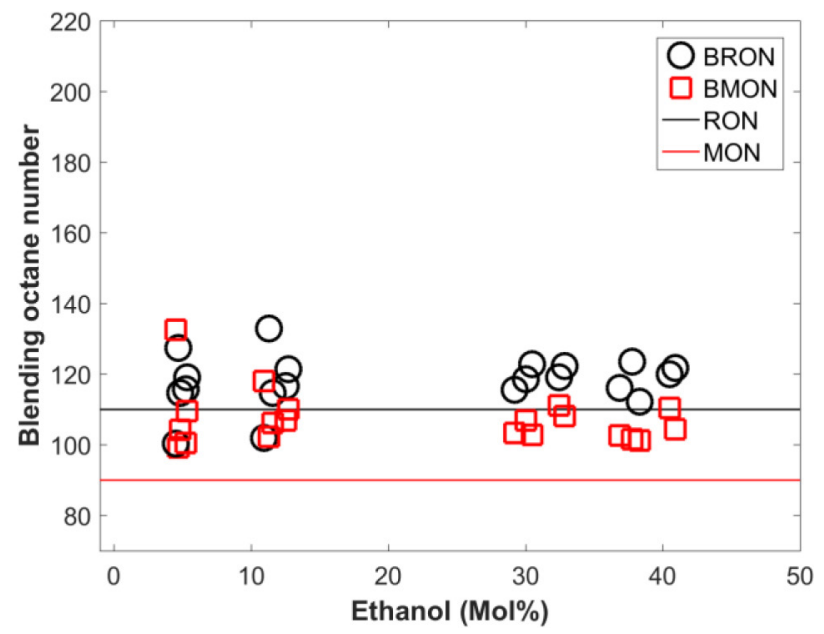

Figure 23. Blending octane number (BRON and BMON) in SI combustion mode versus ethanol percentage on a molar basis. Horizontal lines represent the RON and MON of pure ethanol.

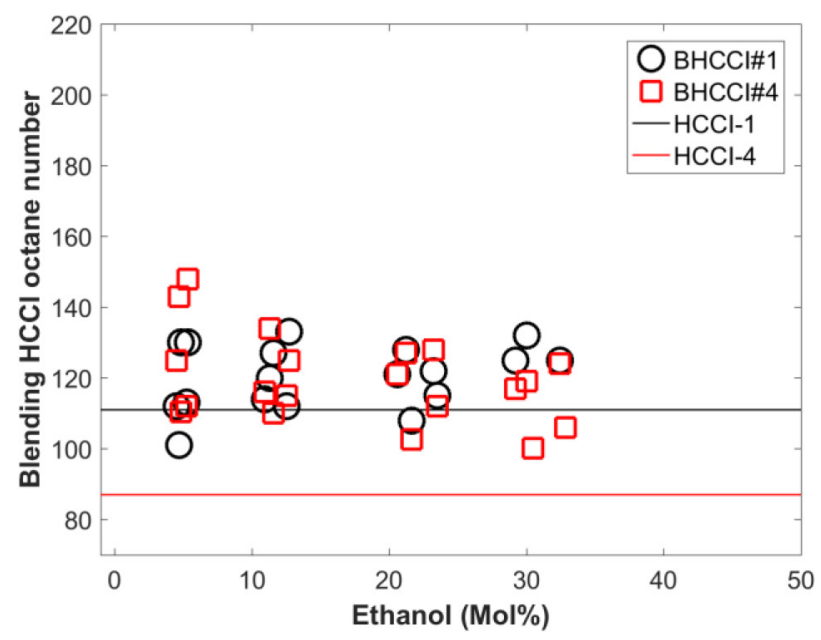

Figure 24. Blending octane number (BHCCI \#1 and BHCCI \#4) in HCCI combustion mode versus ethanol percentage on a molar basis. Horizontal lines represent the HCCI-1 and HCCI-4 of pure ethanol.

\section{Discussion}

The blending of ethanol with five base fuels was examined on both a volume and molar basis. The investigation was carried out for two combustion modes: lean auto ignition (HCCI) and stoichiometric (SI knock). Previous studies have demonstrated that the blending behavior of ethanol in hydrocarbon base fuels is different on a volume and molar basis, e.g. $[\underline{20}, \underline{21}, \underline{23}]$. The results for the SI combustion mode (Fig. 21) are in full agreement with the findings of other researchers, with the exception of some discrepancies in the BMON values on a molar basis (Fig. 23). It has previously been found that the BMON values are grouped around the octane number of pure ethanol (MON 89) [23] . In this study, the BMON values were grouped around 100 (Fig. 23). This indicates that some weak non-linear effects are present. These discrepancies may be due to differences in the compositions of the base fuels between this study and others in the literature.

The non-linear behavior observed when ethanol is blended on volume basis exists for the SI combustion mode [19, 20, 23] . This is also true for the HCCI combustion mode, but the degree of non-linearity varies since the combustion operates in a fuel lean environment (Figs. 22 and 24). Nevertheless, the dependency of ethanol blending on the base fuel composition and octane number is consistent with the findings for the SI combustion mode. When the HCCI combustion mode is considered on a molar basis, the BHCCI \#1 and BHCCI \#4 values are not entirely grouped around the HCCI \#1 and HCCI \#4 values of pure ethanol. This suggests that some non-linear blending behavior occurs from the addition of ethanol.

Overall, there is still no clear consensus as to which blending approach (volume or molar basis) is most suitable for understanding the blending behavior of ethanol. Industry generally follows a volumetric approach, as outlined earlier in the paper. Many industrial processes and economics are also considered on a weight basis, and since the density is known, it is easy to convert to volume. On the other hand, molar blending can often be useful to estimate mixture octane numbers without requiring extensive experimental characterization. 


\section{Conclusions}

The blending of ethanol with five different base fuels was examined in SI (stoichiometric) and HCCI (lean) combustion modes on a volume and molar basis. For non-linear behavior to exist, the BON (BRON and BMON) in the SI combustion mode must be greater than the RON of pure ethanol. In the HCCI combustion mode, the BON (BHCCI \#1, \#2, \#3 and \#4) must be higher than the HCCI fuel number of pure ethanol. The key conclusions are as follows:

- The blending of ethanol on a volumetric basis produced non-linear effects. This occurred for both the SI and HCCI combustion modes.

- The non-linear behavior could be explained using the Blending Research octane number (BRON) and the Blending Motor octane number (BMON). The BRON and BMON values were found to be higher than the RON and MON of pure ethanol, thereby indicating non-linear behavior.

- The base fuel composition and octane number played an important role in the blending behavior of ethanol on a volume basis for both the SI and HCCI combustion modes.

- A much weaker non-linear effect was present for the SI combustion mode when considered on a molar basis.

- For the HCCI combustion mode, the molar blending approach did not appear to follow the same well-established rules that occur for the SI combustion mode.

- Unlike the SI combustion mode, the base fuel composition and octane number appeared to influence the blending octane number for the HCCI combustion mode when considered on a molar basis.

\section{References}

1. Elfasakhany, A., "Investigations on the effects of ethanolmethanol-gasoline blends in a spark-ignition engine: performance and emissions analysis," Engineering Science and Technology, an International Journal, 18:4, 713-719, 2015, doi. org/10.1016/j.jestch.2015.05.003.

2. Sarathy, SM., Oßwald, P., Hansen, N., and Kohse-Höinghaus, K., "Alcohol combustion chemistry," Progress in Energy and Combustion Science, 44:40-102, 2014, doi:10.1016/j. pecs.2014.04.003.

3. Demirbas, A., Balubaid, M., Basahel, A., Ahmad, W. et al., "Octane rating of gasoline and octane booster additives," Petroleum Science and Technology, 33:11, 1190-1197, 2015, doi :10.1080/10916466.2015.1050506.

4. Surisetty, V., Dalai, A., and Kozinski, J., "Alcohols as alternative fuels: An overview," Applied Catalysis A: General, 404:11, 1-11 ,2011, doi.org/10.1016/j.apcata.2011.07.021.

5. Morganti, K., Abdullah, M., Alzubail, A., Viollet, Y. et al., "Improving the Efficiency of Conventional Spark-Ignition Engines Using Octane-on-Demand Combustion. Part I: Engine Studies," SAE Technical Paper 2016-01-0679, 2016, doi: 10.4271/2016-01-0679.

6. Morganti, K., Alzubail, A., Abdullah, M., Viollet, Y. et al., "Improving the Efficiency of Conventional Spark-Ignition Engines Using Octane-on-Demand Combustion - Part II: Vehicle Studies and Life Cycle Assessment," SAE Technical Paper 2016-01-0683, 2016, doi:10.4271/2016-01-0683.
7. Leone, T., Olin, E., Anderson, J., Jung, H. et al., "Effects of Fuel Octane Rating and Ethanol Content on Knock, Fuel Economy, and CO2 for a Turbocharged DI Engine," SAE Int. J. Fuels Lubr. 7(1):9-28, 2014, doi:10.4271/2014-01-1228.

8. Yuhan, H., Guang, H., and Ronghua, H., "Investigation to charge cooling effect and combustion characteristics of ethanol direct injection in a gasoline port injection engine," Applied Energy, 160:, 244-254, 2015, doi.org/10.1016/j. apenergy.2015.09.059.

9. Stein, R., Polovina, D., Roth, K., Foster, M. et al., "Effect of Heat of Vaporization, Chemical Octane, and Sensitivity on Knock Limit for Ethanol - Gasoline Blends," SAE Int. J. Fuels Lubr. 5(2):823-843, 2012, doi:10.4271/2012-01-1277.

10. Lee, S., Speight, J., and Loyalka, S.," Handbook of alternative fuel technologies, Second Edition," Ch: 1(16) and 12 (397), eBook ISBN : 978-1-4665-9457-9.

11. Bhatia, S., "Advanced Renewable Energy Systems,(Part 1 and 2)," Ch: 16 (403), eBook ISBN: 978-1-78242-273-0.

12. Sprei, F., "Boom and bust of flex-fuel vehicles in Sweden," ECEEE Summer study proceedings, 4-169-13 Sprei, 2013.

13. Moriarty, K., "Handbook for Handling, Storing, and Dispensing E85 and Other Ethanol-Gasoline Blends," National Renewable Energy Laboratory (NREL), Golden, CO, GO-102016-4854, 2016.

14. Kalghatgi, G., "Fuel Anti-Knock Quality - Part I. Engine Studies," SAE Technical Paper 2001-01-3584, 2001, doi:10.4271/2001-01-3584.

15. Kalghatgi, G., Algunaibet, I., and Morganti, K., "On Knock Intensity and Superknock in SI Engines," SAE Int. J. Engines 10(3):1051-1063, 2017, doi:10.4271/2017-01-0689.

16. Kalghatgi, G., Morganti, K., Algunaibet, I., Sarathy, M. et al., "Knock Prediction Using a Simple Model for Ignition Delay," SAE Technical Paper 2016-01-0702, 2016, doi:10.4271/201601-0702.

17. Foong, T., Morganti, K., Brear, M., Silva, G. et al., "The octane numbers of ethanol blended with gasoline and its surrogates," Fuel, 115: 727-739, 2014, doi:10.1016/j.fuel.2013.07.105.

18. Chupka, G., Christensen, E., Fouts, L., Alleman, T. et al., "Heat of Vaporization Measurements for Ethanol Blends Up To 50 Volume Percent in Several Hydrocarbon Blendstocks and Implications for Knock in SI Engines," SAE Int. J. Fuels Lubr. 8(2):251-263, 2015, doi:10.4271/2015-01-0763.

19. Rankovic, N., Bourhis, G., Loos, M., and Dauphin, R., "Understanding octane number evolution for enabling alternative low RON refinery streams and octane boosters as transportation fuels,"Fuel, 150: 41-47 , 2015, doi:10.1016/j. fuel.2015.02.005.

20. Anderson, J., Leone, T., Shelby, M., Wallington, T. et al., "Octane Numbers of Ethanol-Gasoline Blends: Measurements and Novel Estimation Method from Molar Composition," SAE Technical Paper 2012-01-1274, 2012, doi:10.4271/2012-01-1274.

21. Ramadan, A., Sarathy, SM., Khurshid, M., and Badra, J., "A blending rule for octane numbers of PRFs and TPRFs with ethanol," Fuel, 180: 175-186, 2016, doi:10.1016/j. fuel.2016.04.032. 
22. Waqas, M., Naser, N., Sarathy, M., Morganti, K. et al., "Blending Octane Number of Ethanol in HCCI, SI and CI Combustion Modes," SAE Int. J. Fuels Lubr. 9(3):659-682, 2016, doi: $10.4271 / 2016-01-2298$.

23. Anderson, J., Kramer, U., Mueller, S., and Wallington, T., "Octane numbers of ethanol- and methanol- gasoline blends estimated from molar concentrations,"Energy \& Fuels, 24:12, 6576-6585 , 2010, doi:10.1021/ef101125c.

24. Truedsson, I., Cannella, W., Johansson, B., and Tuner, M., "Development of New Test Method for Evaluating HCCI Fuel Performance," SAE Technical Paper 2014-01-2667, 2014, doi:10.4271/2014-01-2667.

25. ASTM D2699-13b, "Standard Test Method for Research Octane Number of Spark-Ignition Engine Fuel,"ASTM International, West Conshohocken, PA, 2013, doi: 10.1520/D2699.

26. ASTM D2700-14, "Standard Test Method for Motor Octane Number of Spark-Ignition Engine Fuel,"ASTM International, West Conshohocken, PA, 2016,doi: 10.1520/D2700-16.

27. Truedsson, I., Cannella, W., Johansson, B., and Tuner, M., "Development of New Test Method for Evaluating HCCI Fuel Performance," SAE Technical Paper 2014-01-2667, 2014, doi: $10.4271 / 2014-01-2667$.

28. Silva, R., Cataluña, R., Menezes, E., Samios, D. et al., "Effect of additives on the antiknock properties and Reid vapor pressure of gasoline,"Fuel, 84: 951-959, 2005, doi.org/10.1016/j. fuel.2005.01.008.

29. Singh, E., Waqas, M., Johansson, B., and Sarathy, M., "Simulating HCCI Blending Octane Number of Primary Reference Fuel with Ethanol," SAE Technical Paper 2017-010734, 2017, doi:10.4271/2017-01-0734.

30. Waqas, M., Atef, N., Singh, E., MASURIER, J. et al., "Blending Behavior of Ethanol with PRF 84 and FACE A Gasoline in HCCI Combustion Mmode," SAE Technical Paper 2017-240082, 2017.

31. Foong, T., Morganti, K., Brear, M., da Silva, G. et al., "The Effect of Charge Cooling on the RON of Ethanol/ Gasoline Blends," SAE Int. J. Fuels Lubr. 6(1):34-43, 2013, doi: 10.4271/2013-01-0886.

32. Waqas, M., Naser, N., Sarathy, M., Feijs, J. et al., "Auto-Ignition of Iso-Stoichiometric Blends of Gasoline-Ethanol-Methanol (GEM) in SI, HCCI and CI Combustion Modes," SAE Technical Paper 2017-01-0726, 2017, doi:10.4271/2017-01-0726.

33. Sarathy, S., Kukkadapu, G., Mehl, M., Javed, T. et al "Compositional effects on the ignition of FACE gasoline fuels.," Combustion and Flame, 169, April 171-193, 2016, doi. org/10.1016/j.combustflame.2016.04.010.

\section{Contact}

Prof. Bengt Johansson

Bengt.Johansson@kaust.edu.sa

\section{Acknowledgements}

The authors would like to thank the Clean Combustion Research Center for providing the experimental facilities. This work was supported by competitive research funding from King Abdullah University of Science and Technology (KAUST). The authors also wishe to thank Mohammed Almansour and Ahmad Radhwan (Saudi Aramco) for preparing the test fuels.

\section{Definitions/Abbreviations}
aTDC - After top dead center
BON - Blending octane number
BMON - Blending Motor octane number
BRON - Blending Research octane number
$C$ - Concentration
$C_{\text {base }}$ - Base fuel concentration
$\boldsymbol{C}_{\text {booster }}$ - Booster concentration
CAD - Crank angle degree
CA50 - Crank angle for 50\% heat release
CFR - Cooperative Fuel Research
FACE - Fuels for Advanced Combustion Engines
HCCI - Homogeneous Charge Compression Ignition
HoV - Heat of vaporization
PRFs - Primary Reference Fuels
MON - Motor octane number
ON - Octane number
$\boldsymbol{R} \boldsymbol{c}$ - Compression ratio
RON - Research octane number
SI - Spark-ignition
ST - Spark timing
TDC - Top dead center 


\section{APPENDIX}

\section{Appendix A - Graphical Representation of Non-linear Behavior from Blending Octane Number}

For non-linear behavior to exist, the Blending octane number (BON) values must be greater or less than the Research octane number (RON) and Motor octane number (MON) of pure ethanol. The RON and MON of ethanol is 108 and 89 respectively. If the BON is equal to the RON or MON of ethanol, then non-linear behavior does not exist. Figure A1 presents the graphical representation of linear and non-linear behavior with octane number.

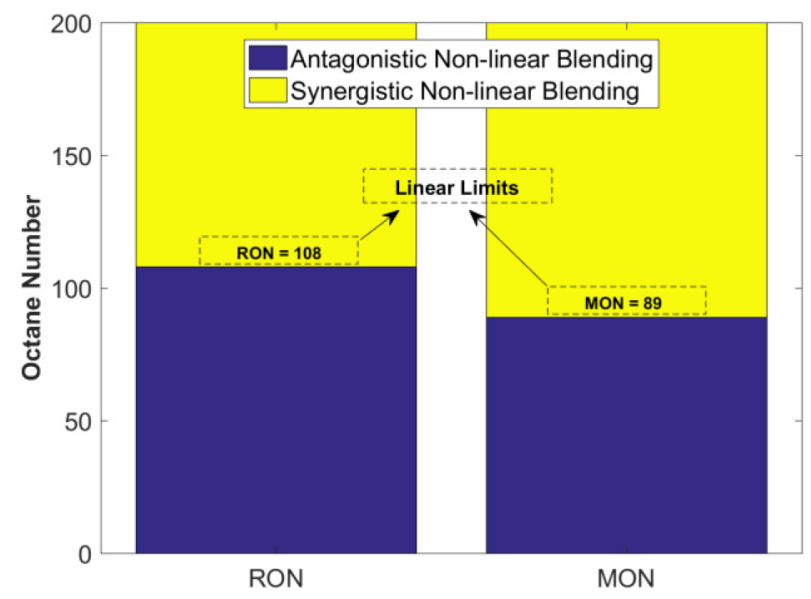

Figure A1. Linear and Non-linear region in the octane number domain.

\section{Appendix B}

Table A1 shows the percentage of energy fraction of ethanol in the fuel blends. The corresponding ethanol percentage by volume in the blends is also shown.

Table A1. Percentage of energy fraction of ethanol in the fuel mixtures.

\begin{tabular}{|c|c|c|c|c|c|}
\hline Volume by $\%$ Ethanol & Ethanol (\%) in FACE I & Ethanol (\%) in FACE J & Ethanol (\%) in FACE A & Ethanol (\%) in PRF 70 & Ethanol (\%) in PRF 84 \\
\hline $0 \%$ & 0.0 & 0.0 & 0.0 & 0.0 & 0.0 \\
\hline $2 \%$ & 1.6 & 1.5 & 1.6 & 1.5 & 1.5 \\
\hline $5 \%$ & 3.9 & 3.7 & 3.9 & 3.9 & 3.9 \\
\hline $10 \%$ & 7.9 & 7.5 & 8.0 & 7.8 & 7.8 \\
\hline $15 \%$ & 12.0 & 11.4 & 12.1 & 11.9 & 11.9 \\
\hline $20 \%$ & 16.2 & 15.5 & 16.3 & 16.0 & 16.0 \\
\hline
\end{tabular}

\section{Appendix C}

Table A2. Constants of best fit lines belonging to Reference curves of four HCCI conditions (Figure 4).

\begin{tabular}{|l|l|l|l|}
\hline Operating conditions & \multicolumn{1}{|c|}{$p$} & \multicolumn{1}{|c|}{$q$} & $r$ \\
\hline HCCI-1(RON) & -2.1832 & 62.031 & -349.16 \\
\hline HCCI-2 & -0.8739 & 26.224 & -102.04 \\
\hline HCCI-3 & -0.9988 & 33.876 & -191.74 \\
\hline HCCI-4(MON) & -0.2641 & 13.232 & -42.738 \\
\hline
\end{tabular}




\section{Appendix D - Uncertainty Analysis}

\section{Spark-Ignited Combustion Mode}

For standard RON and MON testing, the error is $+/-0.7$ and $+/-0.9$ respectively $[\underline{25}, \underline{26}]$. This was applicable to all RON and MON fuel blends tested in this study. Since experiments were only performed on a volume basis, it was decided to add uncertainty bars for all data on volume basis only. Figures A2 $\underline{\mathrm{A} 3}, \underline{\mathrm{A} 4}$ and $\underline{\mathrm{A} 5}$ show plots for the RON, MON and BON (BRON and BMON). The standard error values were used to estimate the uncertainty in the BON.

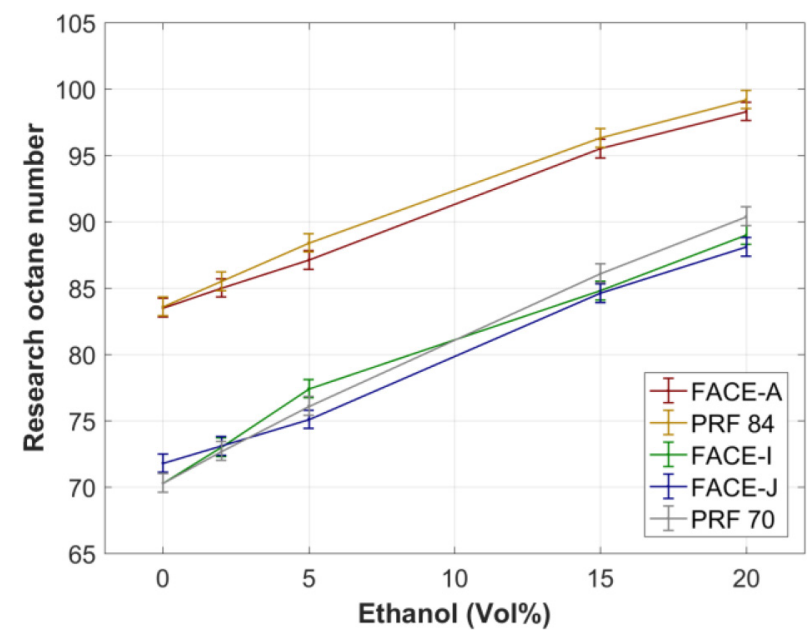

Figure A2. Uncertainty for RON of all base fuels versus ethanol percentage in the SI combustion mode.

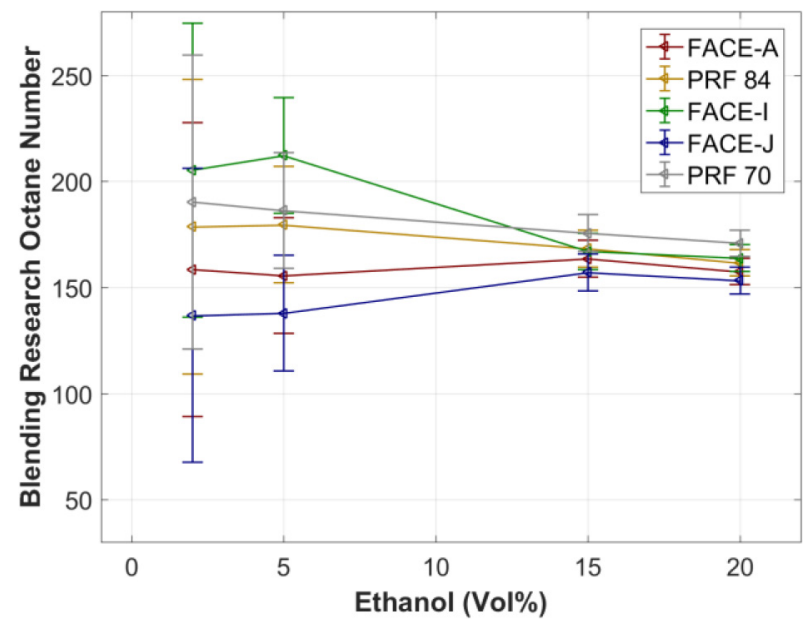

Figure A3. Uncertainty for the Blending Research octane number for all base fuels versus ethanol percentage in the SI combustion mode.

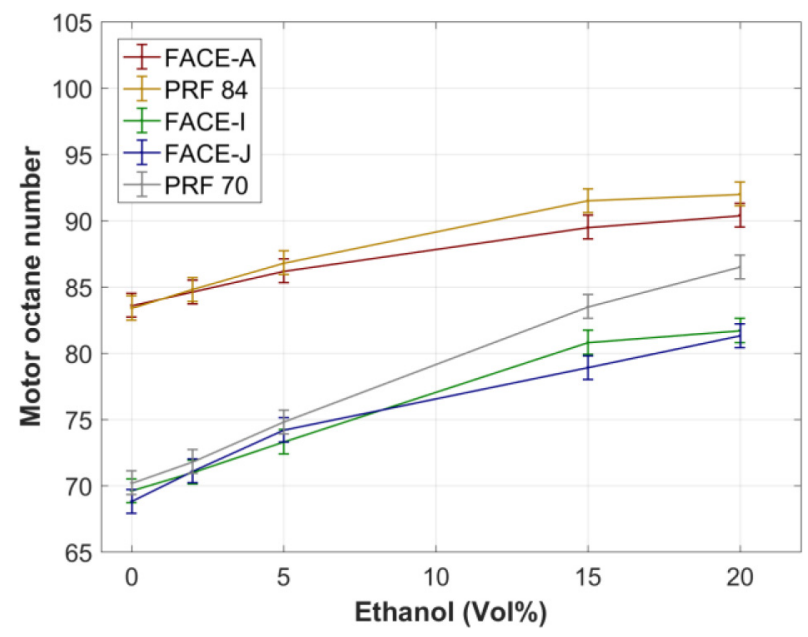

Figure A4. Uncertainty for MON of all base fuels versus ethanol percentage in the SI combustion mode. 


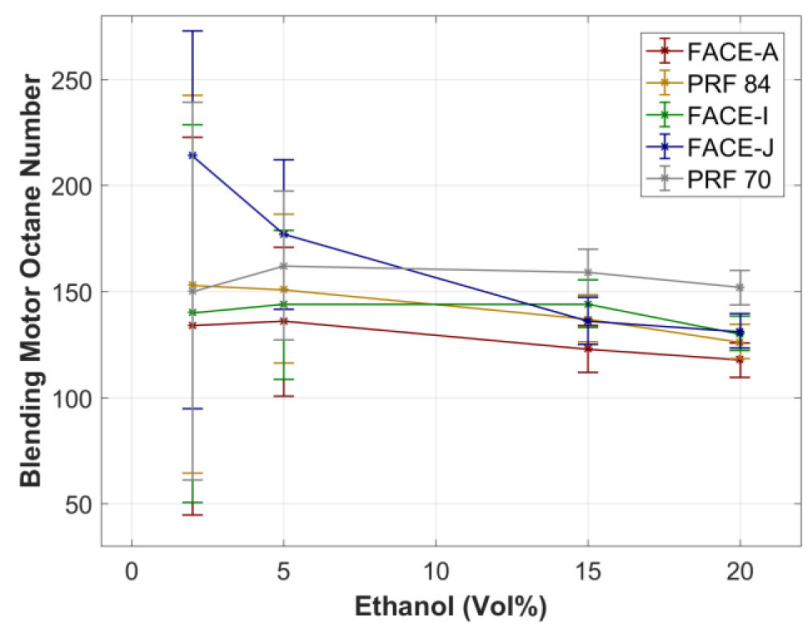

Figure A5. Uncertainty for Blending Motor octane number (BMON) for all base fuels versus ethanol percentage in the SI combustion mode.

\section{Homogeneous Charge Compression Ignition Combustion Mode}

The Transfer function (Figure 4) is used to estimate the error for the HCCI combustion mode. For each line of best fit, an average error was estimated using the data points on the line of best fit. Four different average errors were found for four HCCI numbers. The minimum average error was 0.152 , corresponding to HCCI \# 3 and the maximum average error was 0.281 corresponding to HCCI \# 1 . Based on an average error of 0.281 , an error for BHCCI \# 1 was estimated. Taking into account the worst case scenario, uncertainty analysis were only performed on the BHCCI \#1 octane number. Since the experiments were performed on volume basis, uncertainty bars are presented on volume basis only.

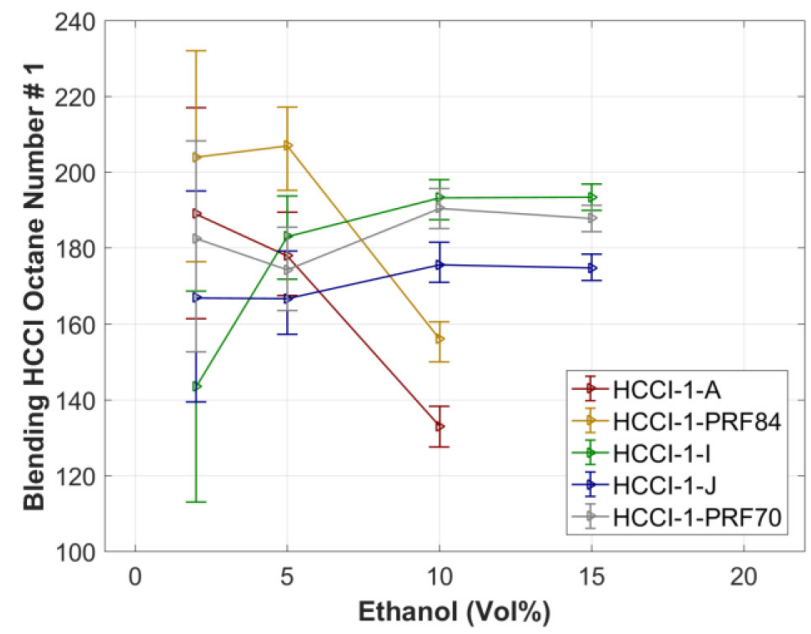

Figure A6. Uncertainty in Blending HCCI \#1 octane number for FACE gasolines and PRFs $\left(600 \mathrm{rpm}, \mathrm{T}_{\mathrm{in}}=52^{\circ} \mathrm{C}\right.$ and $\left.\lambda=3\right)$.

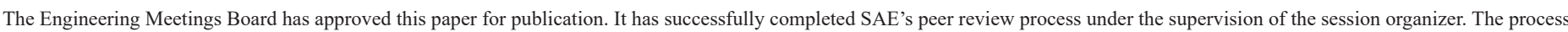
requires a minimum of three (3) reviews by industry experts.

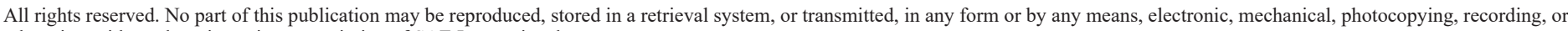
otherwise, without the prior written permission of SAE International.

Positions and opinions advanced in this paper are those of the author(s) and not necessarily those of SAE International. The author is solely responsible for the content of the paper.

ISSN 0148-7191

http://papers.sae.org/2017-01-2256 